\title{
Risco, desastre e educação ambiental: a terceira margem do rio Doce
}

\section{Resumo}

Em 2015, a população da bacia hidrográfica do rio Doce foi surpreendida pelo desastre provocado pelo rompimento da barragem de rejeitos de Fundão, de responsabilidade da mineradora Samarco (Vale/BHP Billiton), o que alterou as condições ambientais e a vida de pessoas e grupos. Esse é o contexto deste artigo, de cunho bibliográfico, que estabelece um diálogo entre os campos da geografia e da educação ambiental, e tem como objetivo refletir sobre a intencionalidade de se pautar, nas práticas escolares, estudos sobre redução dos riscos de desastres (RRD). A análise, sustentada na literatura sobre riscos, na reflexão sobre os impactos desse evento para a população e no saber ambiental, indica possibilidades para que a temática passe a compor os currículos escolares. As conclusões do estudo apontam para a necessidade de atenção para a degradação ambiental e para a inclusão efetiva de estudos sobre riscos de desastres na pauta das políticas públicas no campo da educação com vistas à prevenção, à atuação crítica e à melhoria das condições de vida, em uma perspectiva ambiental.

Palavras-chave: Risco. Desastre. Educação Ambiental. Rio Doce.
Renata Bernardes Faria Campos

PhD em Entomologia pela

Universidade Federal de Viçosa UFV. Professora da Universidade Vale do Rio Doce - UNIVALE. Brasil

rbfcampos@gmail.com

\section{Thiago Martins Santos}

Mestre em Gestão Integrada do Território pela Universidade Vale do Rio Doce - UNIVALE. Professor da UNIVALE. Brasil

thiagomartinsantos@yahoo.com.br

\section{Maria Celeste Reis Fernandes de} Souza

PhD em Educação pela Universidade Federal de Minas Gerais - UFMG. Professora da Universidade Vale do Rio Doce UNIVALE.

Brasil celeste.br@gmail.com.

\section{Eliene Nery Santana Enes}

Mestre em Gestão Integrada do Território pela Universidade Vale do Rio Doce - UNIVALE. Professora da UNIVALE. Brasil eliene.nery@yahoo.com.br 


\title{
Risk, disaster and environmental education: the third bank of the rio Doce
}

\begin{abstract}
In 2015, the population of the Rio Doce basin was overwhelmed by the disaster caused by the disruption of the Fundão Tailings dam, a site owned by the mining company Samarco (Vale/BHP Billiton). This event altered the environmental conditions and the lives of people and groups. This is the context of this bibliographical article, which establishes a dialogue between the fields of geography and environmental education, and aims to reflect on the intentionality of studies on disaster risk reduction (DRR) in school practices. The analysis, based on the literature on risk, on the reflection on the impacts of this event on the population and on environmental knowledge, indicates possibilities for the theme to take part in the school curriculum. The conclusions of the study point to the need for attention to environmental degradation. It also draws attention to the effective inclusion of studies on disaster risks in the agenda of public policies in the education field, aiming at prevention, critical action and improvement of living conditions, from an environmental perspective.
\end{abstract}

Keywords: Risk. Disaster. Environmental Education. Rio Doce.

\section{Para citar este artigo:}

CAMPOS, Renata Bernardes Faria; SANTOS, Thiago Martins; SOUZA, Maria Celeste Reis Fernandes de; ENES, Eliene Nery Santana. Risco, desastre e educação ambiental: a terceira margem do rio Doce. Revista PerCursos, Florianópolis, v. 18, n.36, p. 66 -94, jan./abr. 2017.

\section{DOI: 10.5965/1984724618362017066}

http://dx.doi.org/10.5965/1984724618362017066 


\section{Introdução - às margens do rio Doce}

Este artigo foi produzido às margens do rio Doce por um grupo de pesquisadores que mantêm com esse rio uma relação afetiva e reconhecem sua importância para a vida da população e das cidades que se desenharam à sua volta. Ao longo dos anos, temos, como moradores, usufruído das águas do rio Doce, caminhado às suas margens, nos deixado fotografar tendo-o como cenário, brincado com crianças e plantado árvores à sua volta. E ainda há os que se recordam das inúmeras prainhas que o compunham, das areias brancas que o envolviam e de como ele "era largo", há cerca de três décadas. As evocações que fizemos sobre o rio Doce são marcadas por um "sentimento topofílico" (TUAN, 2012, p. 339).

Esse rio, muito recentemente, figurou na mídia nacional e internacional por ter sido impactado pelo rompimento da barragem de Fundão, situada no município de Mariana, na Região Central de Minas Gerais. A barragem, de responsabilidade da Samarco, mineradora controlada através de uma joint-venture entre a Vale e a BHP Billiton, se rompeu no dia 5 de novembro de 2015, despejando na calha do rio Doce aproximadamente 55.000.000 $\mathrm{m}^{3}$ de rejeitos de minério, que se espalharam por cerca de $600 \mathrm{~km}$ do rio, até chegar ao litoral do Espírito Santo, impactando a fauna, a flora e a vida das pessoas que habitam na bacia hidrográfica do rio Doce. O rompimento da barragem de Fundão é considerado o maior desastre ambiental do Brasil e o pior do mundo envolvendo barragens de rejeitos, e estima-se que seus efeitos serão sentidos ao longo dos anos (MINAS GERAIS/ SEDRU, 2016).

Embora já merecesse a projeção dada pelo desastre e fosse objeto de atenção e ações intencionais no campo legal, das pesquisas, dos movimentos sociais, de escolas e universidades com vistas à promoção da sua sustentabilidade, esse rio foi negligenciado durante décadas, como se suas águas nunca fossem se "esgotar". Assim, além da degradação ambiental continuada, do recente desastre ambiental da mineradora Samarco e com a possibilidade iminente de novos rompimentos, o rio Doce continua "em risco" conforme vários estudos têm demonstrado (PoEMAS, 2015; FUNDAÇÃO ESTADUAL DO MEIO AMBIENTE, 2016; BRASIL, 2016). 
Os efeitos desse desastre e o modo como a população às margens do rio Doce se relacionou com ele foram amplamente divulgados pela mídia, além de terem sido objeto de produções acadêmicas (PoEMAS, 2015; ESPINDOLA et al., 2016; MILANEZ; LOSEKANN, 2016). A convivência com as consequências do desastre ambiental e a possibilidade de novos rompimentos podem ser traduzidas como um sentimento de medo, que no dizer de Yi-Fu-Tuan "são experimentados por indivíduos e, nesse sentido, são subjetivos; alguns, no entanto, são, sem dúvida, produzidos por um meio ambiente ameaçador" (TUAN, 2005, p. 7).

As “paisagens do medo" descritas pelo autor no livro homônimo (TUAN, 2005) são marcadas pelo desconhecimento e, nesse caso, em uma sociedade complexa, tecnologicamente avançada, que parece dispor de "amplos poderes sobre a natureza" (TUAN, 2005, p. 7). Essa sociedade é capaz de conectar instantaneamente pessoas e grupos e colocar em circulação informação - que nem sempre se traduz em conhecimento - acirrando o sentimento de insegurança e o modo como as pessoas vivenciam suas relações com o ambiente.

Esse é o cenário deste artigo cujas reflexões são fruto do estudo sobre a relação que estudantes e suas famílias ${ }^{1}$ estabelecem com o rio antes e depois do desastre da Samarco. É a entrada no campo de pesquisa e o contato cotidiano com a população que vive os efeitos deletérios desse desastre, que implicam situações de risco, incerteza e preocupações que mobilizam esta produção.

O objetivo deste texto, de cunho bibliográfico, é refletir sobre a intencionalidade de se pautar, nas práticas escolares, estudos sobre redução dos riscos de desastres (RRD) em uma perspectiva, tanto da garantia do direito à educação, quanto de aprendizagens específicas, que, evocando Leff (2009), denominamos “saber ambiental”.

O texto estabelece um diálogo entre os campos da geografia e da educação, com o foco na educação ambiental (EA), e se organiza em três seções: a primeira apresenta o

\footnotetext{
${ }^{1}$ Trata-se do estudo intitulado Relação com o saber e educação ambiental: uma pesquisa com estudantes em tempo integral, iniciado por nós no segundo semestre de 2016, cujo objetivo principal é compreender as relações que estudantes, em tempo integral, e suas famílias estabelecem com o rio Doce, como objeto de saber. O estudo conta com o apoio da Universidade Vale do Rio Doce, do CNPq e da FAPEMIG.
} 
referencial teórico adotado para compreender risco de desastre; a segunda delineia as possibilidades educativas sobre risco/desastre vislumbradas a partir do desastre ambiental provocado pelo rompimento da barragem; e a terceira reflete sobre a degradação ambiental da bacia hidrográfica do rio Doce.

\section{Risco: conceitos e abordagens}

As inovações proporcionadas pela ciência e tecnologia implicam tanto a melhoria na qualidade de vida quanto consequências de alta gravidade para a saúde humana e para o meio ambiente. Porém, ciência e técnica não desenvolveram suficientemente sua capacidade de prever e controlar a relação entre os benefícios trazidos e os riscos decorrentes de tais benefícios. As consequências desse descompasso acarretam danos que são, em sua maioria, desconhecidos em longo prazo, mas quando descobertos, tendem a ser irreversíveis. Dessa forma, a sociedade atual lida cada vez mais com novos riscos ecológicos, químicos, nucleares, genéticos e econômicos, gerados a partir do desenvolvimento da ciência e da tecnologia. Esses riscos são produzidos industrialmente, externalizados economicamente, individualizados juridicamente, legitimados cientificamente e minimizados politicamente (BECK, 2011).

Nesse sentido, Beck (2011) aponta que a sociedade atual, que ele denomina sociedade de risco, se caracteriza justamente por se organizar em resposta ao risco. Nesta sociedade, "aos problemas e conflitos distributivos da sociedade [...] sobrepõemse os problemas e conflitos surgidos a partir da produção, definição e distribuição de riscos científico-tecnologicamente produzidos" (BECK, 2011, p. 23). Ocorre, desse modo, uma passagem da lógica de distribuição de riqueza para a lógica da distribuição de riscos.

De fato, nos últimos anos, o interesse pelo tema tem aumentado entre leigos e especialistas, gerando, para os sistemas acadêmicos, uma demanda de maiores preocupações e atividades nas áreas de docência e pesquisa sob o manto da multidisciplinaridade e da interdisciplinaridade (MARANDOLA JR.; HOGAN, 2004). Este interesse relaciona-se com o "o fim de todas as nossas bem cultivadas possibilidades de distanciamento", dado que "a miséria pode ser segregada, mas não os perigos da era 
nuclear" (BECK, 2011, p. 07). O desastre de Chernobyl marca o que Beck chama de o fim dos "outros" dada a susceptibilidade objetiva que implica na sensação de inelutável desamparo diante do perigo nuclear.

Esta sensação de desamparo se reaviva diante do diagnóstico de perigo decorrente da barragem rompida em uma região onde muitas outras barragens da mesma natureza existem. Mais de um ano após o rompimento da barragem de Fundão, ainda sem definição clara da magnitude dos danos ou conhecimento de meios para recuperação dos impactados, confirma-se a denúncia feita por Beck três décadas atrás acerca da "impotência do sistema industrial diante da "natureza" industrialmente integrada e contaminada" (BECK, 2011, p. 09).

O presente texto considera que as abordagens acerca dos riscos são abrangentes, isto é, podem ir desde aquelas bastante objetivas, que tratam risco como uma questão probabilística, até aquelas subjetivistas, que entendem o risco a partir das interações sociais. De modo geral, define-se risco como a contextualização, a possibilidade de materialização de um evento indesejado acontecer. O reconhecimento de uma situação de risco depende de inúmeros fatores, e é mais fácil reconhecer uma situação de risco agudo, dado que no curto prazo é possível perceber a relação direta entre causa e efeito. No caso de riscos crônicos, cujos danos só se manifestam em médio e longo prazo, a situação se torna mais complexa e de difícil identificação. No entanto, em muitos casos os riscos crônicos, aqueles relacionados ao acúmulo de eventos ao longo do tempo, podem ser bem mais significativos do que os riscos agudos (SÁNCHEZ, 2013).

Note-se aqui, que no Brasil, muitos estudos de risco se relacionam com a avaliação de impacto ambiental, obrigatória por lei no processo de licenciamento. ${ }^{2}$ Em sua maioria, tais estudos adotam o enfoque probabilístico, trazendo uma sensação de segurança, por produzir certezas, enquanto se mostram extremamente frágeis dado seu curto espaço de tempo (MARANDOLA JR.; HOGAN, 2004).

Embora tenham natureza multidimensional, os riscos ambientais têm sido reunidos em dois grandes grupos: naturais e tecnológicos (SÁNCHEZ, 2013). No primeiro

\footnotetext{
${ }^{2}$ Lei n. ${ }^{\circ}$ 6.938, de 31 de agosto de 1981.
} 
grupo se enquadram riscos atmosféricos, hidrológicos, geológicos, biológicos e siderais, mas a ação do ser humano deve sempre ser considerada como possível agente deflagrador ou acelerador de processos naturais relacionados com riscos. Assim, os estudos ambientais também podem tratar das modificações de processos naturais que resultem num aumento de riscos naturais, como uma rodovia, que aumenta riscos geológicos de escorregamentos, ou a canalização de um rio, que aumenta os riscos de inundação (SÁNCHEZ, 2013). No segundo grupo se enquadram aqueles cuja origem está diretamente ligada à ação humana, incluindo-se aqui os riscos tecnológicos (explosões e vazamentos) e riscos à saúde (humana ou dos ecossistemas).

Marandola Jr. e Hogan (2004) apontam que o estudo dos riscos relacionados a eventos e sistemas ambientais parecia ser uma das mais importantes e substanciais tendências. De fato, até meados do século XX, os estudos sobre risco se proliferaram principalmente nas chamadas "ciências duras", particularmente nas "ciências da terra", e não nas ciências humanas (MARANDOLA JR.; HOGAN, 2004). Ainda hoje, estimativas e avaliação de riscos se baseiam predominantemente na estimativa probabilística do risco ao qual estão expostas as pessoas na área de influência da instalação, no caso de empreendimentos. A despeito dessa discussão, numa perspectiva tecnológica, as atividades de risco podem causar danos materiais, danos aos ecossistemas ou danos à saúde humana e, não raro, ocorrem os três tipos de danos (SÁNCHEZ, 2013).

Assim, entende-se que, além de ser determinados objetivamente, os riscos podem ser associados em três níveis: (a) negligenciáveis (probabilidade e magnitude pequenas); (b) gerenciáveis (probabilidade e magnitude controláveis de maneira a ser aceitas pela comunidade); (c) não toleráveis (probabilidade e magnitude que, uma vez associadas não são aceitáveis e exigem ações que as minimizem). Entretanto, o conceito de risco aceitável vem sendo debatido há décadas, e algumas pessoas são mais propensas a correr e aceitar riscos, enquanto outras mostram aversão a situações arriscadas. Além disso, a possibilidade de aceitar ou não o risco, depende de uma série de variáveis em cada situação particular. No caso dos riscos ambientais, a dificuldade pode ser ainda maior, pois a fonte de riscos muitas vezes se relaciona com atividades exercidas por um terceiro, e não pelo próprio indivíduo, numa situação que lhe é imposta (SILVA, 2014). 
A ideia de risco muitas vezes está associada ao perigo, mas aqui é importante fazer a distinção, uma vez que o termo "perigo" se refere à situação com potencial para acarretar consequências indesejáveis. Trata-se de característica intrínseca de uma substância ou situação, que por sua vez pode acarretar fonte de risco (SÁNCHEZ, 2013). Podemos entender perigo como um substantivo que ameaça a integridade de um sistema, que pode ser desde o próprio corpo, passando por cidades, bacias até grandes ecossistemas. Tais sistemas podem variar em vulnerabilidade, ${ }^{3}$ aqui entendida como um adjetivo que indica as qualidades desses sistemas de resistir ao perigo (MARANDOLA JR.; HOGAN, 2004).

Nessa perspectiva, o perigo é a ameaça em si, que não é mensurável nem totalmente evidente, enquanto o risco é medido e pode ser classificado de acordo com a natureza de seus agentes, sua fonte geradora ou o sujeito do risco (SILVA, 2014). Segundo Marandola Jr. e Hogan (2004, p. 47) "entender as relações entre o risco, o perigo, a vulnerabilidade e a resiliência, envolve uma discussão sobre as relações de estabilidade e desestabilidade, nem sempre delimitadas claramente, e que não obedecem projeções matemáticas ou geométricas simples". Logo, não deve haver relações causais simples, dado que o risco só pode ser definido após o conhecimento do grau de vulnerabilidades e do perigo, resultando dessa relação. Assim, o risco é uma situação ou condição, portanto é construído socialmente.

A despeito de sua complexidade ou abordagem, todas as definições de risco têm um elemento em comum: a distinção entre a realidade e a possibilidade. Essas definições implicam uma relação causal muitas vezes complexa entre ações e seus efeitos. Assim, efeitos indesejáveis poderão ser evitados ou mitigados se os eventos ou as ações causais puderem ser evitados ou modificados (SILVA, 2014). É nesse sentido que a "avaliação e

\footnotetext{
${ }^{3} \mathrm{~A}$ vulnerabilidade pode ser socioeconômica, cultural, religiosa, ambiental, física, institucional, educacional, política, informacional e comunicacional, entre outras características. No caso de uma comunidade, a vulnerabilidade considera aspectos locais como a capacidade de enfrentamento de situações adversas, que se traduz na combinação de todas as fortalezas, todos os atributos e todos os recursos disponíveis (UNISDR, 2009, p. 10). Note-se que muitos modelos utilizados atualmente para avaliação de vulnerabilidade são, em sua maioria, calcados em indústrias químicas e adaptados para outros setores industriais, inclusive a mineração (SILVA, 2014).
} 
gestão do risco" ou "análise de risco" aparece como uma importante abordagem nos estudos de risco ambiental.

Na análise de risco, o conhecimento científico pode auxiliar a elaboração de políticas públicas. No entanto, esse auxílio deve ser realizado a partir da participação dos pesquisadores na construção dos conhecimentos, em parceria com o poder público e as populações atingidas (MARANDOLA JR.; HOGAN, 2004). Assim, é importante considerar que a maioria dos pesquisadores lida com o risco de uma forma objetiva, enquanto as pessoas, por se encontrarem imersas na situação, apresentam marcas culturais e subjetivas no trato com o risco.

Notadamente, há um descompasso entre a probabilidade de certos eventos acontecerem (estatisticamente) e a percepção das pessoas acerca deles (MARANDOLA JR.; HOGAN, 2004) o que pode ser, e não raro é, fonte de conflitos. A avaliação de riscos é feita em etapas (identificação de riscos, análise de consequências e estimativa de riscos, avaliação de riscos - juízo de valor acerca da importância dos riscos e suas consequências sociais, econômicas e ambientais - e gerenciamento de riscos), processo que implica comunicação, associado também à avaliação de alternativas de minimização dos riscos e suas consequências (SILVA, 2014).

Dagnino e Carpi Júnior (2007, p. 82) orientam que os estudos de risco devem respeitar e valorizar a “[...] percepção e as formas pelas quais os diferentes setores da sociedade podem contribuir para a identificação das situações de risco e prevenção aos danos a elas associados", ao afirmar que a população que convive com o risco é tão indicada para identificá-lo quanto os técnicos e os pesquisadores que o analisam cientificamente. Assim, uma importante abordagem dos estudos de risco, está ligada à “percepção de riscos", cujos estudos têm concluído que, de modo geral, as pessoas percebem e encaram diferentemente as situações de risco, tal como se diferenciam em sua disposição em correr riscos econômicos em investimentos, riscos de vida em esportes radicais, riscos à saúde com o uso de tabaco. As pessoas variam em sua disponibilidade para correr riscos ambientais. 
Segundo Sánchez (2013), pesquisadores das ciências comportamentais têm notado que algumas características parecem ser gerais em diferentes culturas. Uma dessas características é o fato de haver uma preferência intuitiva pelo pensamento determinístico, a experiência e percepção pessoais, assim como as informações disponíveis são muito importantes para a percepção de probabilidade. A familiaridade com situações de risco e o fato de assumi-lo voluntariamente ou por imposição têm influência importante sobre a disposição para sua aceitação. Outro fato é que, de modo geral, as pessoas dão mais importância às possíveis consequências de um evento do que à probabilidade de sua ocorrência. Ou seja, de modo geral, um evento raro é mais preocupante que um evento frequente para grande parte das pessoas, desde que os possíveis danos do primeiro sejam maiores que os danos do segundo.

Outro ponto importante se relaciona com a credibilidade das instituições de gerenciamento de risco que também têm peso para a aceitação ou não de riscos. Além disso, não se pode deixar de tratar do fato de que é mais difícil aceitar uma situação em que os beneficiários não são os mesmos expostos ao risco. E aqui a repartição dos riscos e dos benefícios é fonte de conflitos, dado que na maior parte das situações os beneficiários não são aqueles que deverão suportar os riscos.

A abordagem por "eventos e sistemas ambientais" também tem sido adotada por pesquisadores de risco. Nessa abordagem, considera-se que, para a previsão de riscos, é preciso definir anteriormente a susceptibilidade, o que demanda o conhecimento do ambiente, uma vez que se trata das características intrínsecas das formações. Note-se que estes autores relacionam a susceptibilidade às características do ambiente físico, sendo este aspecto um componente da vulnerabilidade. Nessa perspectiva, entende-se que as intervenções humanas sobre ambientes com distintas susceptibilidades a eventos indesejáveis é que implicarão em risco (MARANDOLA JR.; HOGAN, 2004).

Por outro lado, Cardona, numa visão mais abrangente de vulnerabilidade, afirma que a vulnerabilidade pode ser definida como um fator de risco interno do sujeito ou sistema que está exposto a um perigo e corresponde à sua disposição intrínseca para ser afetada ou a suscetível a um dano. Para esta autora, a suscetibilidade é o componente socioeconômico e demográfico que captura a predisposição de um grupo populacional 
de sofrer danos em face de um fenômeno perigoso, enquanto o componente físico e ambiental da vulnerabilidade é chamado de fragilidade, ou exposição. A falta de resiliência, por sua vez, é apontada como o componente comportamental, comunitário e político, que corresponde à capacidade de um grupo populacional de absorver o choque e se adaptar para voltar a um estado aceitável (CARDONA, 2004).

No Brasil, os riscos climáticos têm se destacado nos estudos da abordagem por “eventos e sistemas ambientais", porque o risco de enchentes e deslizamentos está ligado aos principais conflitos identificados nas cidades. Riscos dessa natureza estão "sobremaneira envolvidos com o fenômeno das cheias, de origem atmosférica mas com fortes componentes geomorfológicos e antrópicos" (MARANDOLA JR.; HOGAN, 2004, p. 37). Particularmente em 2013, a Região Sudeste teve o segundo maior número de atingidos por desastres naturais, após a Região Nordeste. Os resultados apresentados no Anuário de desastre naturais, de 2013 (BRASIL, 2013), foram influenciados em grande parte por desastres hidrológicos, em que eventos de estiagem atingiram o maior número de pessoas, seguidos por chuvas intensas.

Note-se que, entendemos desastre como o "resultado de eventos adversos, naturais ou provocados pelo homem, sobre um ecossistema (vulnerável), causando danos humanos, materiais e/ou ambientais e consequentes prejuízos econômicos e sociais" (CASTRO, 2009, p. 52), podendo ser classificados de acordo com sua origem, evolução e intensidade. É importante frisar que a intensidade do desastre depende não apenas da magnitude do fenômeno adverso, mas principalmente do grau de vulnerabilidade do cenário do desastre e do grupo social atingido.

Assim, muitos estudos se concentram em medições bioquímicas, análise geológica e geomorfológica, estudos de drenagem e de recarga, pluviosidade, análises químicas das águas, perfurações, etc. Porém, foco distinto é dado quando se trata da abordagem de populações em situação de risco. Nesses estudos se incluem tanto aspectos demográficos, tidos como prioritários, quanto aspectos sociais e áreas de risco, na perspectiva das dinâmicas físicas, tidos como capazes de causar danos à população e passíveis de serem controlados por políticas de gestão (MARANDOLA JR.; HOGAN, 2004). Nessa perspectiva, Santos (2015) defende que o desastre é social, pois as ameaças, como 
um terremoto ou tempestade, podem ser naturais, mas o fator determinante para o conceito são as condições de vulnerabilidade de uma população.

Ainda no que diz respeito aos aspectos sociais, Manuel Macias (2015) discute o modo como o conceito de resiliência tem sido incorporado aos estudos sobre o processo risco-desastre e problematiza uma concepção, segundo a qual os sujeitos em situação de vulnerabilidade social são vistos como causadores dos problemas dos quais são vítimas, ignorando-se as relações desiguais entre as populações. O autor problematiza, também, a oposição entre "resiliência", tomada como "força" e "vulnerabilidade", como sinônimo de "fraqueza". Além disso, aponta que as populações encontram diferentes estratégias de sobrevivência coletiva que não podem ser desconsideradas na reflexão sobre a vulnerabilidade.

Ainda sobre a abordagem de riscos por eventos e sistemas ambientais, destaca-se o rompimento de barragens, que contabiliza centenas de casos importantes de rupturas, e mais da metade dos casos se deve ao excesso de carga, embora tecnologias distintas sejam desenvolvidas para a redução desse risco (SANCHEZ, 2013). As consequências da ruptura de uma barragem dependem de sua localização; no entanto, mesmo uma barragem que tenha baixa densidade populacional em suas proximidades, o que implica menor risco de perda de vidas e danos materiais, pode acarretar grandes danos ecológicos.

O rompimento da barragem de Fundão, causador do desastre ambiental na bacia do rio Doce, “consumou o risco já apontado pelo Ministério Público, conforme laudo de 2013. Diferentemente do que estava previsto no EIA-RIMA, o impacto do rompimento da barragem não se restringiu às áreas imediatas à jusante do barramento" (PoEMAS, 2015, p. 12). ${ }^{4} \mathrm{O}$ desastre implicou a destruição das povoações de Bento Rodrigues, onde foram perdidas 19 vidas humanas. Os efeitos negativos se estenderam pelos $663 \mathrm{~km}$ dos rios Gualaxo do Norte, Carmo e Doce, até penetrarem nas águas costeiras do estado do Espírito Santo. Mais de 1.200 pessoas ficaram desabrigadas; pelo menos 1.469 hectares de

\footnotetext{
${ }^{4}$ O Grupo Política, Economia, Mineração, Ambiente e Sociedade (PoEMAS) da Universidade Federal de Juiz de Fora (UFJF) tem o objetivo de compreender o papel social, econômico e ambiental da extração mineral em escala local, regional e nacional. Cf. <http://www.ufjf.br/poemas>. Acesso em: jan. 2017.
} 
terras ficaram destruídos, além de áreas de preservação permanente (APP) e unidades de conservação.

Segundo a Fundação Estadual do Meio Ambiente de Minas Gerais (2016), órgão ambiental do estado de Minas Gerais, foram imensos os danos sociais e ambientais, que ainda estão em contabilização. Os vários estudos divulgados pela imprensa apontaram diferentes causas para esse desastre, em que se incluem desde falhas técnicas de engenharia até as opções administrativas e política econômico-financeira da empresa (PoEMAS, 2015; FEAM, 2016; BRASIL, 2016). Esse não foi um evento isolado, tendo em vista o recente "aumento do número de rompimentos de barragens de rejeitos considerados graves e muito graves” (PoEMAS, 2015, p. 5). Em Minas Gerais, os desastres em barragens de rejeitos sempre foram noticiados pela imprensa;" "nenhum deles, porém, atingiu as proporções do desastre ocorrido no município de Mariana em 2015" (BRASIL, 2016, p. 20).

O volume de rejeitos lançado pela barragem de Fundão supera a magnitude dos dois maiores incidentes ocorridos nas Filipinas em 1982 (28 milhões de $\mathrm{m}^{3}$ ) e 1992 (32,2 milhões de $\mathrm{m}^{3}$ ) (BRASIL, 2015). A estabilidade do solo nas áreas afetadas, assim como o escoamento dos cursos d'água foram comprometidos aumentando o risco de perturbações geomorfológicas adicionais, incluindo deslizamentos de terra, desbarrancamentos e movimentos de massa. Sobretudo é preciso notar que eventos desastrosos como o rompimento da barragem de Fundão devem se tornar mais frequentes no Brasil, em decorrência das recentes mudanças na legislação brasileira ${ }^{6}$, por

\footnotetext{
${ }^{5}$ Podem ser localizados na imprensa, pois tiveram ampla divulgação nacional, o rompimento de barragens de rejeitos em Minas Gerais, tais como: barragem da mina de Fernandinho, do Grupo Itaminas, e da mina do Pico de São Luiz, pertencente à Mineração Brasileira Reunidas (MBR), em Itabirito (1986); barragem operada pela Mineração Rio Verde, no distrito de São Sebastião das Águas Claras, em Nova Lima (2001); barragem Forquilha II, da Vale S.A., em Ouro Preto (2002); vazamento de 1,4 bilhão de litros do líquido negro da barragem das sobras da produção de celulose da Indústria Cataguases de Papel Ltda., em Cataguases (2003); barragem de São Francisco, pertencente à mineradora Rio Pomba Cataguases, em Miraí (2007); barragem da mineradora Herculano, em Itabirito (2014); barragem de Fundão da mineradora SAMARCO, em Mariana (5 nov. 2015).

${ }^{6}$ Sobre essas mudanças, César e Carneiro (2016) afirmam que as mesmas se encontram na contramão da preservação ambiental. Nesse sentido, os autores citam Projeto de Lei n. $^{\circ}$ 5807/13 que versa sobre licenciamento e remodelagem tributária e a Proposta de Emenda à Constituição n..$^{\circ}$ 65/2012 - PEC 65/12, que acrescenta $\circ \S 7^{\circ}$ ao art. 225 da Constituição, para assegurar a continuidade de obra pública após a concessão da licença ambiental; a Lei n. ${ }^{\circ}$ 21.972/16, de 21 de janeiro de 2016 que instituiu o licenciamento
} 
isso são prioritárias e imprescindíveis medidas para fazer face aos riscos agudos e crônicos que se estabelecem nesse cenário (FERNANDES et al., 2016).

Por fim, destaca-se a importância no processo de gerenciamento ambiental da comunicação sobre os riscos e problemas que afetam o meio ambiente:

[...] as empresas não percebem muitos dos efeitos impactantes de suas ações sobre o meio biogeofísico e socioeconômico, as organizações governamentais de controle ambiental, muitas vezes, não percebem as boas intenções e as ações efetivas das empresas para otimizar seus impactos, os promotores de justiça frequentemente não dispõem de sistemas interpretativos confiáveis da relação causa/efeito de problemas ambientais e o grande público geralmente não confere muita credibilidade aos outros participantes, criando uma série de preconceitos. Os resultados da interação desses fatores será o desenvolvimento de ineficiências operacionais e o sepultamento de estratégias de ações anteriormente tidas como alternativas confiáveis. (SILVA, 2014, p. 913)

Com efeito, a RRD, implica compreender as tramas nas quais risco/desastre se encontram: do avanço da ciência e da tecnologia, que pode trazer benesses, mas implica riscos às pessoas e ao ambiente; do contraponto entre objetividade e subjetividade; da contextualização dos conflitos socioambientais; da possibilidade de cálculo e previsão que se defronta com o imponderável; da cultura e do modo como diferentes pessoas e grupos compreendem e vivenciam situações de risco de desastre; da susceptibilidade do ambiente e da ação humana; das condições de resiliência ou vulnerabilidade da população; da produção e geração de conhecimento.

Lembrando Macias, reafirmamos que a vulnerabilidade coloca em pauta a necessidade de pensar na redução de desastres de maneira estrutural propiciando o "desenvolvimento da sociedade em suas diferentes esferas, a produtiva, a política e a

concomitante e a Licença Ambiental Simplificada. "Merece atenção especial o conteúdo estabelecido no artigo 10 do Decreto n. ${ }^{\circ}$ 46.993/2016, que isenta os órgãos estaduais no licenciamento e na fiscalização ambiental de aspectos relativos à segurança estrutural e operacional das barragens de rejeitos" (CÉSAR; CARNEIRO, 2016, p. 200). 
educativa"7 (MACÍAS, 2015, p. 318). Portanto, considerando a pluralidade de interpretações e o caráter multidimensional do risco, entende-se ser necessária uma abordagem interdisciplinar para sua melhor compreensão. Nessas tramas é que a ação educativa com vistas à RRD se apresenta como uma alternativa potencializadora como se discute na próxima seção deste artigo.

\section{Saber ambiental: a terceira margem do Rio}

O título deste artigo é inspirado no texto de Nóvoa (2011) "Pedagogia: a terceira margem do rio". O autor, evocando o conto de Guimarães Rosa A terceira margem do rio, nos convoca não só a abandonar as dicotomias tão presentes no campo educacional (aprendizagem ou ensino; conteúdo ou método; aprovação ou reprovação etc.) que, segundo ele, “empobrecem o debate educativo", mas também a nos aventurar pela terceira margem do rio que "não consiste em encontrar terras novas, mas em adquirir novos olhares" (NÓVOA, 2011, p. 14). Essas considerações do autor nos parecem férteis para refletirmos sobre as contribuições da educação ambiental nos cenários de risco de desastre ambiental, como o vivenciado pelas populações da bacia hidrográfica do rio Doce.

Em seu trabalho Riscos ambientais: conceitos e aplicações, Dagnino e Carpi Júnior (2007) nos apontam que o risco, dado à sua natureza multidimensional, tem sido objeto de estudo de diversas ciências e campos do conhecimento, o que lhe possibilita uma variedade de definições e de possibilidades teórico-metodológicas. A ideia probabilística de risco - de que um evento indesejado venha ou não ocorrer -, muito aceita e difundida na cultura ocidental, se diferencia da noção de risco dos chineses, por exemplo, para quem o risco está associado à ideia de perigo/oportunidade. Ou seja, o risco traz consigo novas possibilidades de uma vida melhor. Portanto, nos equilibramos nessa tensão entre os efeitos dos riscos ambientais e a busca de possibilidades de reversão, inclusive das

\footnotetext{
7 (...) “el desarrollo de la sociedad em sus diferentes esferas, la productiva, lapolítica, la educativa”(MACÍAS, 2015, p. 318). Tradução nossa.
} 
situações de risco, e é nesse equilíbrio tenso que a educação emerge como potencializadora tanto da crítica quanto da busca de alternativas.

Hoje vivemos os impactos derivados do desastre causado pelo rompimento da barragem de Fundão e o risco de sua ampliação, caso outras barragens se rompam. Além disso, temos riscos derivados, tais como surgimento de doenças, contaminação da água por metais, inundações, desabastecimento de água, assoreamento, estiagens mais severas, extinção de espécies, instabilidade geológica, perda de serviços ambientais, entre outros (ESPINDOLA et al., 2016).

Esse contexto espera por respostas mais efetivas em diferentes âmbitos (jurídicos, ambientais, no campo da saúde, de reordenamento populacional e educacionais). No campo educacional, na bacia hidrográfica do rio Doce, considerando a continuidade dos riscos, é possível afirmar que a "aprendizagem pré-catástrofe vai ocorrer cada vez mais dentro de um ambiente pós-desastre" (SELBY; KAGAWA, 2012, p. 30). O ambiente pósdesastre exige um novo olhar sobre as práticas educativas escolares e sobre o modo como risco/desastre tem sido tratado (ou silenciado) no contexto escolar.

No campo legal, a educação ambiental, amparada por diferentes ordenamentos, tem sido responsável por pautar, de modo transversal nos currículos, o debate ambiental. Esses diferentes documentos, referendados pelas Diretrizes Curriculares Nacionais para a Educação Ambiental (BRASIL. MEC, 2012) afirmam que a práxis da EA se dará por meio de uma educação cidadã, responsável, crítica, participativa, envolvendo conhecimentos científicos e o reconhecimento dos saberes tradicionais. Constitui-se como "elemento identitário que demarca um campo de valores e práticas, mobilizando atores sociais, comprometidos com a prática político-pedagógica contra hegemônica" (BRASIL, MEC, 2012, p. 2).

O modo de efetivação da EA nas escolas tem ocorrido em três alternativas não excludentes: projetos, inclusão de disciplina específica no currículo, temática transversal (BRASIL, 2012). O texto das Diretrizes torna obrigatória sua oferta em todos os níveis e modalidades de ensino, enfatiza a transversalidade temática e, não se limitando ao meio ambiente, problematiza os efeitos decorrentes de um modelo de desenvolvimento 
econômico e social que instaura as desigualdades sociais. Nessa direção, engloba tanto a justiça social e ambiental quanto as preocupações com a qualidade de vida.

O texto legal enfatiza a necessidade de responder às

[...] inquietações humanas frente à complexidade da crise ambiental que não se restringe aos problemas como a extinção de espécies, à contaminação do ar, à escassez da água e ao efeito estufa - mas atinge a existência humana, degradando a qualidade de vida e os relacionamentos sociais. (BRASIL. MEC, 2012, p. 13)

O referido documento enfatiza a preocupação com os riscos socioambientais locais e globais, e destaca a contribuição da EA na prevenção de desastres ambientais e proteção das comunidades. Riscos/desastres ambientais são cada vez mais iminentes, como afirmam os autores trazidos na primeira seção deste texto, e podem ser considerados como resultado de uma tecnociência, que precisa ser repensada "pelas suas implicações no ser humano e no planeta, em razão da ambivalência de seus resultados, que trazem benefícios, mas igualmente riscos" (ALVARENGA et al., 2011, p. 4).

Diante disso, uma pergunta se coloca: como torná-los preocupação efetiva e objeto de estudo nas práticas escolares, se tendencialmente os conhecimentos ambientais oscilam entre as disciplinas de geografia e ciências naturais (SELBY; KAGAWA, 2012), ou se pulverizam nos projetos institucionais que, em grande medida, tendem a buscar uma conscientização ambiental sem aprofundamento de conhecimentos e saberes específicos?

Alguns autores do campo da $\mathrm{EA}^{8}$ afirmam que tratar desse tema é um movimento holístico, um conhecimento que repousa na complexidade dos saberes e dos modos de organização de vida de pessoas e grupos:

Se a ciência tem perdido suas certezas e suas capacidades preditivas, se se tem derrubado a possibilidade de construir um mundo planificado

\footnotetext{
${ }^{8}$ Cf. Carvalho (1998; 2006); Reigota (2009); Leff (2000).
} 
centralmente sobre as bases de uma racionalidade científica e uma racionalização dos processos sociais, então a educação não apenas deve preparar as novas gerações para aceitar a incerteza do desastre ecológico e para gerar capacidades de resposta ao imprevisto; também deve preparar novas mentalidades capazes de compreender as complexas inter-relações entre os processos objetivos e subjetivos que constituem seu modo de vida, a fim de gerar habilidades inovadoras para a construção do inédito. (LEFF, 2009, p. 20)

Entretanto, a escola atual, continua "moderna", no sentido do conhecimento veiculado que repousa na excessiva disciplinarização, marca da “ciência normal” (KUHN, 2013) expressa na fragmentação dos currículos escolares; no modo de pensar o conhecimento, ainda pautado no pensamento dicotômico e que carrega as marcas dessa mesma ciência paradigmática ao separar homem/natureza, sujeito/objeto de conhecimento, razão/emoção, e ao confiar, ao modo cartesiano, na linearidade do saber, na ordenação clara e distinta das ideias e jamais se fiar nos sentidos (DESCARTES, 1983).

Assim, um primeiro movimento necessário para uma mudança de olhar, como aponta Nóvoa, se faz nas tentativas de produzir, ainda que fissuras, nessa forma escolar que cerceia tempos, espaços, diferenças, que tende às certezas, portanto, dificilmente considera riscos ou "corre riscos".

Em 2012 foi divulgado pela UNICEF e pela UNESCO o documento Redução de risco de desastre nos currículos escolares (SELBY; KAGAWA, 2012). O documento apresenta um estudo de caso de 30 países que contemplam intencionalmente nos currículos a temática dos riscos de desastres ambientais (terremotos no Haiti, Armênia, Cazaquistão; tsunami nas Ilhas Maldivas e no Sri Lanka; enchentes no Camboja). Além disso, o documento contempla preocupações com desastres naturais e tecnológicos como nas propostas da Rússia, da França e da Costa Rica.

A introdução desse documento expressa dois propósitos para a inclusão da RRD no currículo. O primeiro é a garantia do direito à educação, posto que, como afirma o documento, no "caso de um desastre são as crianças as mais afetadas, já que a interrupção no sistema de ensino afeta um direito fundamental” (p. 4). O segundo é a aposta na educação como "um instrumento de construção do conhecimento, de 
habilidades e atitudes necessárias para se preparar e lidar com desastres, bem como para ajudar os alunos e a comunidade a voltar a uma vida normal” (p. 4), ou seja, potencializar sua resiliência. São também esses os propósitos que apontamos neste texto para a inclusão da RRD no currículo das escolas cuja população foi vítima do desastre ambiental provocado pelo rompimento da barragem de rejeitos de mineração da Samarco.

Como moradores da bacia hidrográfica do rio Doce e pesquisadores, constatamos as consequências na garantia do direito à educação. Inicialmente, acompanhamos a interrupção das aulas nas primeiras semanas pós-desastre, período no qual a pluma de rejeitos se deslocava pelo rio e atingia as populações da cidade e do campo, comprometendo o serviço de abastecimento de água ou destruindo escolas, como é o caso do distrito de Bento Rodrigues. Além disso, a qualidade da água consumida nas escolas gera insegurança sobre os seus efeitos na saúde dos discentes e docentes, além de desconfiança dos laudos relativos à qualidade da água, o que reforça a paisagem do medo diante da incerteza.

As experiências com a inclusão intencional nos currículos escolares da RRD nos países pesquisados se dão em vários enfoques: abordagem mais direcionada por livro didático; abordagem por projetos; abordagens baseadas em competências; abordagem simbiótica/transversal; abordagem como evento especial (SELBY; KAGAWA, 2012). Essas abordagens estão descritas no documento e de certo modo são norteadas pelo desenvolvimento de competências, habilidades e atitudes acompanhando o estabelecido no Marco de Hyoto (2005): da garantia de programas que enfrentam problemas locais, na busca de reduzir ao mínimo as ameaças, na garantia da igualdade de gênero e do acesso a grupos considerados vulneráveis.

A leitura territorial do município de Governador Valadares, Minas Gerais, atingido fortemente pelo desastre da Samarco nos permite apresentar algumas possibilidades para a inclusão intencional da RRD nos currículos escolares. Governador Valadares é considerado o município mais populoso da bacia hidrográfica do rio Doce e tem esse rio como a única fonte de captação de água de abastecimento. Dos 228 municípios que compõem a bacia, apenas Coronel Fabriciano, Ipatinga e Governador Valadares, em Minas Gerais, e Colatina e Linhares, no Espírito Santo, possuem uma população superior a 
100.000 habitantes. Cerca de $85 \%$ dos municípios que formam a bacia têm uma população de até 20.000 habitantes (CBH-DOCE, 2014).

O direcionamento para as possibilidades apresentadas, além dos autores já citados, parte da premissa de que precisamos educar para um "saber ambiental" (LEFF, 2009), necessário em uma região marcada por ciclos predatórios que contribuíram fortemente para a sua degradação ambiental (ESPINDOLA, 2005; 2012; COELHO, 2011), o que vem se acirrar com o desastre ambiental no rio Doce, que tem um papel central na vida da população. Foi o rio que criou as condições para a existência da cidade.

O saber ambiental, conforme propõe Leff (2000; 2009), está inscrito em uma concepção de educação ambiental fundada na visão holística da realidade, na complexidade e na interdisciplinaridade. O autor problematiza a racionalidade moderna ao integrar "o conhecimento racional e o conhecimento sensível, os saberes e os sabores da vida" (LEFF, 2009, p. 17); poderíamos dizer os saberes e os dissabores da vida, considerando a experiência subjetiva com o desastre da Samarco.

Importa refletir que o "saber ambiental" se sustenta em outras bases de conhecimento e ousa integrar e validar a "relação entre vida e conhecimento" (LEFF, 2009, p. 17). Assim, o "saber ambiental” implica um rompimento com o modo de se relacionar com o saber na escola e busca superar a fragmentação, provocando-nos à conexão dos saberes. Portanto, a uma mudança individual no modo de conceber o que denominamos "conhecimento".

O autor faz outras afirmações que nos parecem pertinentes para refletir sobre as RRD nas práticas escolares, com vistas a um saber ambiental: (a) reafirmação da historicidade; (b) encontro das identidades, reconhecimento dos territórios de vida; (c) construção de uma rede de relações de outredade; (d) confrontação da "objetividade do conhecimento com as diversas formas do real" (LEFF, 2009, p. 19); (e) consideração sobre o sujeito e a cultura; (f) construção de estratégias para a apropriação do mundo. O saber ambiental 
[...] é uma epistemologia política que busca dar sustentabilidade à vida; constitui um saber que vincula os potenciais ecológicos e a produtividade neguentrópica do planeta com a criatividade cultural dos povos que o habitam. O saber ambiental muda o olhar do conhecimento e com isso transforma as condições do saber no mundo na relação que estabelece o ser com o pensar e o saber, com o conhecer e o atuar no mundo. $O$ saber ambiental é uma ética para acarinhar a vida. (LEFF, 2009, p. 18)

Considerando o desastre ambiental como um evento extremo, uma experiência até então não vivenciada na bacia com efeitos semelhantes e o novo de uma situação até então não experimentada, o que causou certa inércia e estranhamento da população de Governador Valadares diante do desastre e seus riscos, propõe-se a inclusão da RRD nos currículos escolares, tratando-a neste primeiro momento como um "evento especial", por meio do qual as escolas, em um tempo a ser definido, se voltem para a situação de risco/desastre da Samarco (Vale/BHP Billiton).

$\mathrm{Na}$ realidade das escolas municipais, essa é uma perspectiva viável pela implantação da Escola em Tempo Integral (ETI), em 2010, que ampliou a jornada diária escolar para 8 horas de atividades $^{9}$ e que tem como um dos eixos do currículo o Protagonismo e a Sustentabilidade. Conforme o caderno 1, orientador da proposta, a estratégia curricular é “[...] o desenvolvimento da identidade social e respeito à diversidade para o desenvolvimento sustentável" (GOVERNADOR VALADARES, 2009, p. 5). Portanto, de modo explícito, a questão ambiental compõe o currículo da ETI. E se antes já não era possível na escola ignorar a questão da água, no contexto de vida presente e no futuro para as cidades localizadas às margens do rio Doce, essa é uma questão premente.

O "evento especial" pode ter "uma influência catalítica e de galvanização no desenvolvimento do currículo" (SELBY; KAGAWA, 2012, p. 18), além de oferecer a estudantes e suas famílias a possibilidade de compreender diferentes aspectos envolvidos no desastre e suas consequências, até então desconhecidos. Além disso,

\footnotetext{
${ }^{9}$ A ampliação da jornada escolar diária está prevista na Lei de Diretrizes de Bases da Educação Nacional (BRASIL, 1996) e no Plano Nacional de Educação (BRASIL, 2014) e compreende sete horas ou mais de atividades escolares na escola, ou em articulação com outros espaços da cidade.
} 
marcado por uma epistemologia política, buscará construir uma rede solidária que favorecerá posicionamentos da população frente ao risco de desastre tecnológico como o vivenciado.

Se a bacia do rio Doce já constituía uma preocupação pela redução do volume e da qualidade das águas, essa preocupação se vê visivelmente aumentada pós-rompimento da barragem, o que impõe aos habitantes do município esforços no sentido de compreender a importância de renovação do rio e de preservação ambiental, além da inserção cidadã comprometida em defesa do rio Doce.

Constatamos que persiste a preocupação da população com relação à qualidade da água distribuída pelo Serviço Autônomo de Água e Esgoto (SAAE). Assim que a pluma de rejeitos de mineração chegou ao município no dia 8 de novembro de 2015, houve a interrupção da captação de água do rio pelo SAAE e, consequentemente, a distribuição de água tratada foi interrompida, fato que durou alguns dias. O serviço de abastecimento foi retomado no dia 16 de novembro, com o tratamento da água bruta com polímero de acácia-negra, capaz de separar a água da lama, antes do tratamento convencional. No entanto, a desconfiança sobre a presença de metais pesados na água tratada além do permitido pela legislação tem gerado temor aos valadarenses, que ainda resistem em consumir a água do SAAE, optando pelo consumo de água mineral, quando possível.

Nesse sentido, a escola pode ser um lócus disseminador de estudos e debates sobre reportagens que circularam e circulam na mídia sobre a qualidade da água; pode propiciar análises de dados diversos disponibilizados pelos órgãos públicos; pode propiciar a escuta de especialistas, pesquisadores, pescadores, camponeses e outros sujeitos que lidam cotidianamente com a água, ou cuja subsistência dependa do rio, dentre outras possibilidades.

Cabe um olhar para a escola: que experiências são vivenciadas na escola e como elas se aproximam ou se distanciam das questões ambientais, da questão da água e do rio Doce? Há um momento anterior ao rompimento da barragem, cuja preocupação era a diminuição do volume da água e, no momento atual, as preocupações se voltam para a biodiversidade, a qualidade da água consumida pela população, os impactos econômicos, 
sociais e ambientais. Cabe, portanto, valorizar o que a escola já faz, e ampliar as possibilidades analíticas das práticas escolares.

Por sua vez, como cidadãos da cidade, os estudantes e suas famílias vivenciaram a falta de água para o consumo, enfrentaram filas para receber a água mineral distribuída pela Samarco (Vale-BHP) em diferentes pontos da cidade, até o dia 22 de janeiro de 2016, e estão à mercê das decisões judiciais que obrigam a Samarco a retomar a distribuição de água mineral; buscam outras estratégias de captação de água - água da chuva, poços para captação de águas subterrâneas, etc. e ainda vivem os dilemas de consumir ou não a água disponível via SAAE. No campo, essa realidade se agrava, pois além do consumo humano, a água se mostrou inadequada para o consumo dos animais e comprometeu a irrigação. As consequências do desastre ambiental demandam dos habitantes do município, na cidade e no campo, outras experiências e aprendizagens necessárias para a sobrevivência.

Desse modo, em uma atitude investigativa pode-se pensar na possibilidade de que se explorem as estratégias criadas pelos/as estudantes e suas famílias frente ao risco da falta de água, provocado pelo rompimento da barragem, e como se preparam para a eventualidade de novos rompimentos. Abre-se, portanto, um leque de possibilidades para que a escola promova situações de aprendizagens que possibilitem aos estudantes e suas famílias a compreensão sobre o contexto do desastre. Essa compreensão implica conhecimentos sobre as causas e as consequências em uma análise mais abrangente. Para tal, se fazem necessários conhecimentos sobre biodiversidade, degradação ambiental, lençóis freáticos, assoreamento, efeitos dos metais pesados encontrados na água sobre o organismo de animais, plantas e humanos, aspectos históricos da bacia hidrográfica do rio Doce. Os laudos técnicos e os dados matemáticos neles contidos precisam ser discutidos pelos estudantes e famílias contribuindo para a diminuição da insegurança em relação a esses dados e às “certezas” neles contidas.

A população se vê também diante das indenizações disponibilizadas pela mineradora Samarco às pessoas que sofreram danos relacionados à interrupção do abastecimento e da distribuição de água nas primeiras semanas pós-rompimento da barragem: $O$ que elas acarretam, quais as consequências e qual o sentido político do 
ressarcimento oferecido? Há que se interrogar como o desastre atingiu a vida das pessoas também no campo profissional; esclarecer sobre a legislação ambiental, quando pertinente; e recuperar aspectos da memória, da cultura e da história, buscando apreender o sentimento topofílico para se construir a esperança, as formas de luta e a resistência necessárias à promoção da justiça ambiental, via educação ambiental.

Esta proposição que consideramos "evento especial” é emergencial assim como a situação vivenciada pelas populações atingidas pelo rompimento da barragem de fundão. Consideram-se aqui as análises apresentadas por Sulaiman e Aledo (2016) sobre a educação para a redução de riscos de desastres que, sob as lógicas da prevenção, como fator de proteção e informação como geradora de conhecimentos, "valoriza o conhecimento técnico-científico acumulado sobre desastres e deixa de considerar o conhecimento local, experienciado para esse processo" (SULAIMAN; ALEDO, 2016, p. 15). Além disso, há que se considerar o modo desigual como os grupos se defrontam com as situações de desastre, que afeta de modo mais contundente os já vulneráveis, e buscar a sustentabilidade.

A inclusão da RRD no currículo escolar abriria, pois, "o caminho para uma educação para prevenção de natureza emancipadora e crítica que permitisse o questionamento coletivo das causas sociais produtoras de risco" (SULAIMAN; ALEDO, 2016, p. 19).

\section{Para concluir}

A degradação ambiental no vale do rio Doce é histórica, e os riscos ambientais da bacia hidrográfica do rio Doce não constituem uma novidade. Assim, ao elencar algumas proposições para o enfrentamento do risco/desastre, marcadamente pós-desastre ambiental da Samarco (Vale/BHP Billiton), via educação ambiental, cremos ser necessário enfatizar a necessidade de um novo olhar para a degradação ambiental e para a bacia hidrográfica. Se antes do desastre nos preocupávamos com a quantidade da água ou com as ocasionais enchentes, hoje nos assolam a qualidade da água, a lama que continua a percorrer o rio, os efeitos e riscos decorrentes desse desastre. 
Além da degradação ambiental, convivemos com o risco tecnológico e somos tomados de incerteza, vivemos a incerteza, como moradores às margens do rio Doce. $\mathrm{O}$ exercício simbólico de entrada no rio que fizemos neste texto evocando o conto $A$ terceira margem do rio é uma convocação para que efetivamente entremos no movimento do rio e, imersos nesse movimento, criemos possibilidades para a bacia hidrográfica do rio Doce, o que implica pensar que essas possibilidades são a nossa própria existência e de outros que virão após cada um de nós.

Desse modo, a proposição de RRD nos currículos ultrapassa a situação de evento “especial” aqui apresentada e requer outros posicionamentos tanto nas práticas escolares quanto na busca dos diferentes grupos, dos movimentos sociais da cidade e do campo, e na compreensão sobre o modo como se relacionam com o rio antes e após o desastre. O rio talvez nos convoque mais uma vez à pesca de ideias, atitudes, valores, sentimentos, percepções sobre o sentido do rio Doce para nós e para os grupos que com ele mantêm uma relação afetiva que clama posicionamentos.

Esperamos que este artigo possa contribuir para apontar pistas para as políticas públicas, especialmente no campo educacional, recolocando a educação ambiental como uma possibilidade inclusiva dos sujeitos frente ao risco que tem efeitos nas práticas cotidianas e, portanto, configurado de diferentes modos as condições da existência.

Agradecimentos: Universidade Vale do Rio Doce, CNPq e FAPEMIG.

\section{Referências}

ALVARENGA, Thereza. et al. Histórico, fundamentos filosóficos e teórico-metodológicos da interdisciplinaridade. In: PHILIPPI JR., Arlindo; SILVA NETO, Antônio.

Interdisciplinaridade em ciência, tecnologia \& inovação. Barueri, SP: Manole, 2011. p. 368.

BECK, Ulrich. Sociedade de risco: rumo a uma outra modernidade. Editora 34, 2011.

BRASIL, 1996. Lei n 9.324, de 20 de dezembro de 1996. Dispõe sobre as diretrizes e bases da educação nacional. Diário Oficial da União, Brasília, DF, 23/12/1996. 
BRASIL. Ministério da Integração Nacional. Secretaria Nacional de Defesa Civil. Centro Nacional de Gerenciamento de Riscos e Desastres (Cenad). Anuário brasileiro de desastres naturais 2013. Brasília: Cenad, 2013. Disponível em: <http://www.mi.gov.br/c/document_library/get_file?uuid=fee4007a-abob-403e-bb1a8aa0038563ob\&groupld=10157>. Acesso em: 01 fev. 2017.

BRASIL. Lei $n^{\circ} n^{\circ} 13$ 005/2014, de 25 de junho de 2014. Aprova o Plano Nacional de Educação - PNE e dá outras providências. Brasília, 2014.

BRASIL. Ministério do Meio Ambiente. Agência Nacional de Águas . Encarte especial sobre a bacia do Rio Doce. Rompimento da barragem em Mariana/MG., Brasília: SRP, 2016. Disponível em: <http://www.cbhdoce.org.br/wpcontent/uploads/2016/03/EncarteRioDoce_21_03_2016_1.pdf >. Acesso em: $01 \mathrm{fev.} 2017$.

BRASIL. Lei n. ${ }^{\circ} 6.938$, de 31 de agosto de 1981. Dispõe sobre a Política Nacional do Meio Ambiente, seus fins e mecanismos de formulação e aplicação. Diário Oficial da República Federativa do Brasil, Brasília, DF, 1981.

BRASIL. Ministério da Educação. Conselho Nacional de Educação. Resolução n. ${ }^{\circ}$ 02, de 15 de junho de 2012. Estabelece as Diretrizes Curriculares Nacionais para a Educação Ambiental. Brasília: MEC, 2012.

CARDONA, Omar Dario. The need for rethinking the concepts of vulnerability and risk from a holistic perspective: a necessary review and criticism for effective risk management. Mapping vulnerability: Disasters, development and people, v. 17, 2004.

CARVALHO, Isabel. Em direção ao mundo da vida: interdisciplinaridade e educação ambiental. Brasília: IPÊ, 1998 (Cadernos de Educação Ambiental).

CARVALHO, Isabel. Educação ambiental: a formação do sujeito ecológico. São Paulo: Cortez, 2006.

CASTRO, Antônio. Glossário de defesa civil estudos de riscos e medicina de desastres. Brasília: Ministério da Integração Nacional, 2009. Disponível em: http://www.defesacivil.mg.gov.br/images/documentos/Defesa\%20Civil/manuais/GLOSSARI O-Dicionario-Defesa-Civil.pdf; Acesso em: 20 fev. 2017

COELHO, Marco. Rio Doce: a espantosa evolução de um vale. Belo Horizonte: Autêntica, 2011.

COMITÊ DA BACIA HIDROGRÁFICA DO RIO DOCE (CBH-DOCE). [site].Governador Valadares, 2016.Disponível em: <www.cbhdoce.org.br>. Acesso em: 21 fev. 2016. 
DAGNINO, Ricardo; CARPI JÚNIOR, Salvador. Risco ambiental: conceitos e aplicações.

Climatologia \& Estudos da Paisagem, Rio Claro, SP, v. 2, n. 2, p. 50-87, 2007. Publicação semestral da Universidade Estadual Paulista (Unesp). ISSN 1980-654X.

DESCARTES, René. Discurso do método: meditações; objeções e respostas; as paixões da alma; Cartas. 2. ed. Tradução de J. Guinsburg e Bento Junior. São Paulo: Abril Cultural, 1983.

ESPINDOLA, Haruf. Sertão do Rio Doce. Bauru, SP: EDUSC, 2005.

ESPINDOLA, Haruf; GUIMARÃES, Diego; SIQUEIRA, Natalia. Esse rio do ferro e da floresta tem nome de Doce: poder, capital e apropriação da natureza. In: ENCONTRO REGIONAL DA ANPUH (MG), n. 18, Mariana (MG), 24 a 27 de julho de 2012. [Anais online].2012. Disponível em:

<http://www.encontro2012.mg.anpuh.org/resources/anais/24/1340832480_ARQUIVO_Tex toCompletoHARUFANPUH2012revisto.pdf >. Acesso em 16 fev. 2017.

ESPINDOLA, Haruf et al. Desastre da Samarco no Brasil: desafios para a conservação da biodiversidade. Fronteiras: Journal of Social, Technological and Environmental Science, v. 5, p. 72-100, 2016.

FERNANDES, Geraldo. et al. Deep into the mud: ecological and socio-economic impacts of the dam breach in Mariana, Brazil. Natureza \& Conservação, v. 14, n. 2, p. 35-45, 2016. Publicação da Associação Brasileira de Ciência Ecológica e Conservação (ABECO). ISSN $1679-0073$.

\section{FUNDAÇÃO ESTADUAL DO MEIO AMBIENTE. Inventário de barragens do Estado de} Minas Gerais. Belo Horizonte, 2016. p. 55, 2016. Disponível em:

<http://www.feam.br/images/stories/2016/RESIDUOS_MINERA\%C3\%87\%C3\%83O/Invent\%C3 \%A1rio_de_Barragens_2015_Final_Vo1.pdf>. Acesso em 20 fev. 2017

GOVERNADOR VALADARES. Secretaria Municipal de Educação. Escola em tempo integral. Caderno 1. Governador Valadares, 2009.

INSTITUTO BRASILEIRO DO MEIO AMBIENTE E DOS RECURSOS NATURAIS RENOVÁVEIS. Diretoria de Proteção Ambiental. Coordenação Geral de Emergências Ambientais. Laudo técnico preliminar: impactos ambientais decorrentes do desastre envolvendo o rompimento da barragem de Fundão, em Mariana, Minas Gerais. [Brasília], 2015. Disponível em:

<http://www.ibama.gov.br/phocadownload/noticias/noticias2016/laudo_tecnico_prelimin ar_lbama.pdf>. Acesso em: $01 \mathrm{fev.} 2017$. 
KUHN, Thomas. A estrutura das revoluções científicas. 12. ed. São Paulo: Perspectiva, 2013.

LEFF, Enrique. Complexidade, interdisciplinaridade e saber ambiental. In: PHILIPPI JR., Arlindo (Org.). Interdisciplinaridade em ciências ambientais. São Paulo: Signus, 2000. p. 309-335.

LEFF, Enrique. Complexidade, racionalidade ambiental e diálogo de saberes. Educação e Realidade. v.34, n.3, p. 17-24, set./dez. 2009.

MACÍAS Medrano. Jesús Manuel. Crítica de la noción de resiliência en el campo de estudios de desastres. Criticism of resilience concept in the field of disaster studies. Revista Geográfica Venezolana, v. 56, n.2, p.309-325, 2015.

MARANDOLA JR., Eduardo; HOGAN, Daniel. O risco em perspectiva: tendências e abordagens. Geosul, Florianópolis, v. 19, n. 38, p. 25-58, 2004. Publicação da Universidade Federal de Santa Catarina. ISSN 2177-5230.

MILANEZ, Bruno; LOSEKANN, Cristiana (Orgs.). Desastre no Vale do Rio Doce: antecedentes, impactos e ações sobre a destruição. Rio de Janeiro: Folio Digital: Letra e Imagem, 2016.

MINAS GERAIS. SEDRU. Relatório: avaliação dos efeitos e desdobramentos do rompimento da barragem de Fundão em Mariana-MG. Belo Horizonte, 2016. Disponível em: <www.urbano.mg.gov.br/images/NOTICIAS/2016/relatorio_final.pdf $>$. Acesso em: 21 fev. 2016.

NÓVOA, António. Pedagogia: a terceira margem do rio. São Paulo: Instituto de Estudos Avançados da Universidade de São Paulo, 2011. Disponível em: <www.iea.usp.br.textos>. Acesso em: 25 jan. 2017.

POEMAS: antes fosse mais leve a carga: avaliação dos aspectos econômicos, políticos e sociais do desastre da Samarco/Vale/BHP em Mariana (MG), 2015. Disponível em: http://www.ufjf.br/poemas/files/2014/07/PoEMAS-2015-Antes-fosse-mais-leve-a-cargavers\%C3\%A30-final.pdf Acesso em: 25 jan. 2017.

REIGOTA, Marcos. O que é educação ambiental. 2. ed. São Paulo: Brasiliense, 2009.

SÁNCHEZ, Luis. Avaliação de impacto ambiental: conceitos e métodos. São Paulo: Oficina de Textos, 2013.

SANTOS, Juliana. A redução de vulnerabilidades como estratégia no enfrentamento de desastres. Razón y Palabra, v. 91, p. 1-24, 2015. 
SELBY, David; KAGAWA, Fumiyo. Redução do risco de desastres nos currículos escolares: estudos de casos de trinta países. Barcelona, Espanha: UNICEF/UNESCO 2012.

SILVA, Carlos. Gerenciamento de riscos ambientais. In: PHILIPPI JR, Arlindo; ROMERO, Marcelo; BRUNA, Gilda (Orgs.). Curso de gestão ambiental. Barueri: Manole, 2014.

SULAIMAN, Samia; ALEDO, Antonio. Desastres naturais: convivência com o risco. Estudos Avançados, São Paulo, v.30, n.88, 2016. Publicação quadrimestral do Instituto de Estudos Avançados (IEA) da Universidade de São Paulo (USP).

TUAN, Yi-Fu. Paisagens do medo. São Paulo: UNESP, 2005.

TUAN, Yi-Fu. Topofilia: um estudo da percepção, atitudes e valores do meio ambiente. São Paulo: DIFEL, 2012.

UNITED NATIONS INTERNATIONAL STRATEGY FOR DISASTER REDUCTION. Terminología de reducción de riesgo de desastres: estrategia Internacional para la Reducción de Desastres de Las Naciones Unidas, 2009. Disponível em:

<http://www.unisdr.org/we/inform/terminology>. Acesso em: 01 fev. 2016.

Recebido em: 20/02/2017

Aprovado em: 08/06/2017

Universidade do Estado de Santa Catarina - UDESC

Centro de Ciências Humanas e da Educação - FAED

Revista PerCursos

Volume 18 - Número 36 - Ano 2017 revistapercursos@gmail.com 